\title{
Visão atual do abuso sexual na infância e adolescência
}

\author{
Current view of sexual abuse in childhood and adolescence \\ Luci Pfeiffer ${ }^{1}$, Edila Pizzato Salvagni²
}

\section{Resumo}

Objetivo: Revisar os aspectos peculiares que envolvem o abuso sexual na infância e na adolescência, oferecendo subsídios para o diagnóstico e conduta corretos, salientando suas conseqüências a curto e longo prazo.

Fontes de dados: Revisão da literatura nacional e internacional através do MEDLINE e LILACS, utilizando como palavras-chave "abuso" e "violência sexual" (1988 a 2005), aliada à experiência clínica dos autores.

Síntese dos dados: $\mathrm{O}$ abuso sexual tem um impacto muito grande na saúde física e mental da criança e do adolescente, deixando marcas em seu desenvolvimento, com danos que podem persistir por toda vida. Sua deteç̧ão precoce possibilita o tratamento e acompanhamento adequados, com a minimização das seqüelas. $O$ envolvimento familiar deve ser levado em conta. Todas as distorções de relacionamento necessitam ser avaliadas e tratadas, para que se interrompa sua continuidade, que se dará no abuso intergeracional e na possibilidade de revitimização. A identificação da violência doméstica e dos sinais de alerta físicos e psicológicos para o abuso sexual fazem parte da avaliação.

Conclusões: Todo pediatra precisa estar apto a decodificar os sinais e sintomas que a criança e o adolescente vítimas de abuso sexual trazem consigo. Necessita ser proficiente na escuta, no exame clínico e no tratamento. Deve estar capacitado para o manejo psicológico da situação de violência e ter conhecimento da legislação e meios de proteção legais e sociais existentes em sua comunidade, sempre necessários na assistência às vitimas de abuso sexual.

J Pediatr (Rio J). 2005;81(5 Supl):S197-S204: Abuso sexual, violência sexual, incesto, infância e adolescência.

\begin{abstract}
Objective: To review single aspects, which involve sexual abuse in childhood and adolescence, giving subsidies for accurate diagnosis and management, emphasizing the short and long-term consequences.
\end{abstract}

Sources of data: National and international literature review of the MEDLINE and LILACS databases, using abuse and sexual violence as keywords (1988 to 2005), in addition to the authors' theoretical and practical experiences.

Summary of the findings: Sexual abuse has a great impact on child and adolescent physical and mental health, affecting development and causing lifelong damage. Its early detection allows for adequate treatment and follow-up, with minimum consequences. Family involvement must be taken into consideration, and any kind of improper relationship should be evaluated and treated, so that it can be discouraged and eliminated; otherwise, intergenerational abuse will result and probably recur. The identification of domestic violence and of physical and psychological warning signs concerning sexual abuse is part of the general evaluation.

Conclusions: Pediatricians should be able to identify the signs and symptoms sexually abused children and adolescents carry with them. They have to listen carefully to the patients, perform the necessary clinical examination and establish the proper treatment. They should also be able to deal with psychological aspects and have enough knowledge about the laws and about legal and social protection measures, which are always very useful in assisting victims of sexual violence.

J Pediatr (Rio J). 2005;81(5 Supl):S197-S204: Sexual abuse, sexual violence, incest, childhood and adolescence.
1. Médica, especialista em crianças e adolescentes. Vice-presidente, Departamento Científico de Segurança da Criança e Adolescente, Sociedade Brasileira de Pediatria. Presidente, Departamento Científico de Segurança da Criança e Adolescente, Sociedade Paranaense de Pediatria. Membro do Comitê Estadual de Enfrentamento à Violência contra Criança e Adolescente do Estado do Paraná. Membro da Coordenação Municipal da Rede de Proteção às Crianças e aos Adolescentes em Situação de Risco para Violência de Curitiba, PR.

2. Professora adjunta, Faculdade de Medicina, Universidade Federal do Rio Grande do Sul (UFRGS). Médica pediatra, Hospital Materno Infantil Presidente Vargas/Centro de Referência no Atendimento Infanto-Juvenil (CRAI). Médica pediatra, Programa de Proteção à Criança, Hospital de Clínicas de Porto Alegre, RS.

Como citar este artigo: Pfeiffer L, Salvagni EP. Visão atual do abuso sexual na infância e adolescência. J Pediatr (Rio J). 2005;81 (5 Supl):S197S204.

\section{Introdução}

Das estruturas familiares, segundo Lévi-Strauss, em Las estructuras elementales del parentesco ${ }^{1}$, definem-se como relações de parentesco elementares a sangüínea, que acontece entre irmãos; a de filiação, entre pais e filhos; e a de aliança, como a dos genros, noras, padrastos e madrastas.

Segundo Freud, em Totem y Tabú ${ }^{2}$, para as duas primeiras relações parentais, as normas legais de cuidados existem desde as mais remotas eras, antes mesmo das leis, onde dois princípios fundamentais sempre regeram a convivência entre as pessoas - a proibição do canibalismo e a proibição do incesto. 
Esses princípios são transmitidos de diversas formas, como pela educação, pela religião ou cultura, e nenhum ser humano que viva em sociedade pode afirmar desconhecer essa lei, que é passada de geração a geração. É essa regra maior que deveria ser respeitada também nas relações de aliança, onde o que determina o comportamento de um frente ao outro seria uma questão de formação.

A prática sexual, cada vez mais propagada e difundida, pode se apresentar em formas distorcidas de relacionamentos, com a busca desenfreada de novas situações e modalidades, não importando se isso significa ir além do respeito ao outro.

Em todos os tempos, o domínio do mais forte sob o mais fraco foi exercido sob as diversas formas de poder, nas diferentes esferas da sociedade, desde as políticas e estatais, às sociais e familiares. A essa relação de poder, de busca dos excessos, do diferente e até mesmo do anormal, soma-se a pouca importância dada às crianças e aos adolescentes e às conseqüências dos maus-tratos dos adultos sobre eles.

Dessa forma, mesmo com a evolução dos princípios morais e legais em defesa das crianças e adolescentes, os casos de abuso sexual não deixaram de acontecer, nem passaram a ser vistos de maneira uniforme pela sociedade como um crime que deixa seqüelas, muitas vezes irreparáveis.

Define-se abuso ou violência sexual na infância e adolescência como a situação em que a criança, ou o adolescente, é usada para satisfação sexual de um adulto ou adolescente mais velho, (responsável por ela ou que possua algum vínculo familiar ou de relacionamento, atual ou anterior), incluindo desde a prática de carícias, manipulação de genitália, mama ou ânus, exploração sexual, voyeurismo, pornografia, exibicionismo, até o ato sexual, com ou sem penetração, sendo a violência sempre presumida em menores de 14 anos (adaptado de ABRAPIA, 1997) ${ }^{3}$.

De difícil suspeita e complicada confirmação, os casos de abuso sexual na infância e adolescência são praticados, na sua maioria, por pessoas ligadas diretamente às vítimas e sobre as quais exercem alguma forma de poder ou de dependência.

Nem sempre acompanhado de violência física aparente, pode se apresentar de várias formas e níveis de gravidade, o que dificulta enormemente a possibilidade de denúncia pela vítima e a confirmação diagnóstica pelos meios hoje oferecidos pelas medidas legais de averiguação do crime.

Efeitos psicológicos do abuso sexual podem ser devastadores, e os problemas decorrentes do abuso persistem na vida adulta dessas crianças ${ }^{4}$.

É um fenômeno universal que atinge todas as idades, classes sociais, etnias, religiões e culturas e pode ser considerado como qualquer ato ou conduta baseado no gênero, que cause dano ou sofrimento físico, sexual ou psicológico à vítima e, em extremos, a morte.

Sobreviventes do abuso sexual freqüentemente repetem o ciclo de vitimização, perpetrando o abuso sexual intergeracional com seus próprios filhos ${ }^{5}$.
A possibilidade de transitar da passividade da experiência para a atividade e aplicar ao mundo externo a agressão que Ihe foi conferida permite que a criança "se desforre por procuração".

Assim, estabelece-se um processo defensivo, o qual tende a se perpetuar: a identificação com o agressor como uma maneira psíquica de sobreviver ao abuso. A vítima, ao se igualar com o seu agressor e se converter em molestadora, torna o abuso sexual um legado passado à próxima geração de vítimas ${ }^{6}$.

De outra forma, poderá apresentar a possibilidade de estabelecer uma relação abusiva consigo mesmo, como acontece nos casos de revitimização 7,8 .

\section{Os números da violência}

O abuso sexual infantil é considerado, pela Organização Mundial da Saúde (OMS), como um dos maiores problemas de saúde pública. Estudos realizados em diferentes partes do mundo sugerem que $7-36 \%$ das meninas e $3-29 \%$ dos meninos sofreram abuso sexual ${ }^{9}$.

A sua real prevalência é desconhecida, visto que muitas crianças não revelam o abuso, somente conseguindo falar sobre ele na idade adulta ${ }^{10}$.

As estatísticas, portanto, não são dados absolutos. Trabalha-se com um fenômeno que é encoberto por segredo, "um muro de silêncio", do qual fazem parte os familiares, vizinhos e, algumas vezes, os próprios profissionais que atendem as crianças vítimas de violência ${ }^{11}$.

Acrescente-se a isso que países com limitados recursos socioeconômicos podem não ser capazes de manejar todos os relatos de suspeita de abuso sexual ou coletar dados referentes a eles ${ }^{12}$.

Pesquisas em países europeus indicam que 6-36\% de meninas e $1-15 \%$ de meninos sofreram experiências sexuais abusivas antes dos 16 anos. De forma similar, em estudos realizados nos EUA, com uma amostra de 935 pessoas, $32,3 \%$ das mulheres e $14,2 \%$ dos homens revelaram abuso sexual na infância, e 19,5\% das mulheres e $22,2 \%$ dos homens sofreram violência física ${ }^{13}$.

Dados da Polícia Civil - Secretaria da Justiça e da Segurança do Estado do Rio Grande do Sul - apontam que, em 2002, 1.400 crianças foram vítimas de violência; destas, 872 ou $62 \%$ foram vítimas de violência sexual. Em 2003, 1.763 foram vítimas de violência; destas, 1.166 ou $66,14 \%$ de violência sexual. De janeiro a julho de 2004, de 525 crianças vítimas de violência, 333 ou $63,43 \%$ estavam relacionadas à violência sexual ${ }^{14}$.

Esses números, extremamente cruéis, são indicativos que a violência sexual é a que tem sido mais denunciada e acompanhada por essa Secretaria, não se podendo considerá-los, no entanto, como um índice de prevalência dentro da proporção de todos os tipos de maus-tratos a que podem ser submetidos crianças e adolescentes.

Dados do programa Rede de Proteção às Crianças e Adolescentes em Situação de Risco para Violência, da cidade de Curitiba (PR), evidenciam 1.356 notificações de 
maus-tratos no ano de 2003. Destas, $17,6 \%$ foram casos de abuso sexual, sendo $75,6 \%$ do sexo feminino e $24,4 \%$ do sexo masculino (Tabela 1$)^{15}$.

Tabela 1 - Número e percentual de notificações segundo tipo de violência do programa Rede de Proteção, Curitiba, 2003

\begin{tabular}{lcc}
\hline Tipo de Violência & $\mathbf{n}$ & $\mathbf{\%}$ \\
\hline Negligência & 537 & 39,6 \\
Física & 476 & 35,1 \\
Sexual & 238 & 17,6 \\
Psicológica & 90 & 6,6 \\
Abandono & 15 & 1,1 \\
Total & 1.356 & 100 \\
\hline
\end{tabular}

Fonte: CE/SMS - Banco de dados da Rede de Proteção, Curitiba, 2003. Nota: Em uma notificação $(0,1 \%)$ não houve o registro do tipo de violência.

A violência sexual apresentou a maior prevalência como forma de violência doméstica, com $75,2 \%$ dos casos. Em $24,8 \%$ das notificações, o abuso aconteceu fora da residência da vítima. Porém, mesmo assim, a quase totalidade desses casos foi cometida por pessoas que mantinham relacionamento de confiança com a vítima. Isso demonstra a distorção que a sociedade mantém nesse tipo de violência, quando remete habitualmente a imagem do agressor ao estranho, marginal ou psicopata de rua.

É preciso que se leve em conta, também, que o abuso sexual ocorre para os dois sexos, sendo maior a incidência no sexo feminino, até por ser culturalmente o mais aceito, tanto para o ato em si, como para a denúncia. As estatísticas internacionais apontam para $10 \%$ dos casos referentes ao sexo masculino. Nos dados do Programa Rede de Proteção de Curitiba, das 238 notificações de violência sexual acompanhadas no ano de $2003,24,4 \%$ eram de meninos ${ }^{15}$.

\section{Por que as crianças e adolescentes se calam}

$\mathrm{Na}$ assistência à criança e adolescente vítimas de maustratos, há que se considerar que, em aproximadamente $20 \%$ de todos os casos, existe o abuso sexual, sempre acompanhado das agressões psicológicas, como em todas as formas de violência nessa faixa etária.

Os casos mais freqüentes de violência sexual até a adolescência são decorrentes de incesto, ou seja, quando o agressor tem ou mantém algum grau de parentesco com a vítima, determinando muito mais grave lesão psicológica do que na agressão sofrida por estranhos.

Trata-se de uma forma de violência doméstica que usualmente acontece de forma repetitiva, insidiosa, em um ambiente relacional favorável, sem que a criança tome, inicialmente, consciência do ato abusivo do adulto, que a coloca como provocadora e participante, levando-a a crer que é culpada por seu procedimento (o abuso).
O agressor usa da relação de confiança que tem com a criança ou adolescente e de poder como responsável para se aproximar cada vez mais, praticando atos que a vítima considera inicialmente como de demonstrações afetivas e de interesse. Essa aproximação é recebida, a princípio, com satisfação pela criança, que se sente privilegiada pela atenção do responsável. Este lhe passa a idéia de proteção e que seus atos seriam normais em um relacionamento de pais e filhas, ou filhos, ou mesmo entre a posição de parentesco ou de relacionamento que tem com a vítima.

As abordagens, que se tornam cada vez mais freqüentes e abusivas, levam a um sentimento de insegurança e dúvida, que pode permanecer por muito tempo, na dependência da maturidade da vítima, de sua estrutura de valores e conhecimentos, além da possibilidade ou não que teria de diálogo e apoio com o outro responsável, habitualmente favorecedor, consciente ou não, da violência.

Quando o agressor percebe que a criança começa a entender como abuso ou, ao menos, como anormal seus atos, tenta inverter os papéis, impondo a ela a culpa de ter aceitado seus carinhos. Usa da imaturidade e insegurança de sua vítima, colocando em dúvida a importância que tem para sua família, diminuindo ainda mais seu amor próprio, ao demonstrar que qualquer queixa da parte dela não teria valor ou crédito. Passa, então, à exigência do silêncio, através de todos os tipos de ameaças à vítima e às pessoas de quem ela mais gosta ou depende. $O$ abuso é progressivo; quanto mais medo, aversão ou resistência pela vítima, maior o prazer do agressor, maior a violência ${ }^{16}$.

Sentindo-se desprotegida pelo outro responsável, habitualmente a mãe, que permitiu a aproximação do abusador, insegura por imaginar que realmente não seria ouvida ou acreditada, envergonhada tanto pelo que passa, como pela sua impossibilidade de denunciar, por seu amor próprio reduzido e, ainda, ameaçada por aquele de quem habitualmente depende física e emocionalmente, ela se cala, muitas vezes para toda sua vida.

As situações de abuso homossexual são relatadas em $10 \%$ dos casos de violência sexual dentro da literatura internacional. No programa Rede de Proteção às Crianças e Adolescentes em Situação de Risco para Maus-Tratos, Curitiba, 2002 e $2003^{15}$, esses casos foram encontrados em $21 \%$ das notificações de abuso sexual. Esse tipo de violência ocorre mais freqüentemente entre o responsável do sexo masculino e o menino ou o adolescente, sem que isso necessariamente constitua um comportamento definitivo homossexual do agressor ou da vítima. Habitualmente, faz parte de um quadro de abuso geral, em caráter pedofílico, onde também as meninas da casa sofrem o mesmo tipo de agressão.

\section{Um pacto familiar de silêncio}

Como parte de uma doença familiar, para que haja a denúncia do abuso sexual, é preciso que haja uma ruptura do equilíbrio doméstico que as pessoas se impõem, em uma distorção relacional denominada família incestuosa. Nos casos mais comuns e dentro de uma estrutura patriarcal de 
poder trazida das gerações anteriores, a mãe passa a ocupar o papel de silent partner - no qual tem uma participação muda em um quadro geral de violência.

Felizardo et al., no artigo "Modelos Teóricos de Interpretação para Violação do Incesto"17 - fazem referência a Kaufmann et al., que em 1954 já descreviam um perfil comum dessas mães: quase todas tiveram uma mãe dominante, fria e emocionalmente distante, que rejeitou as filhas, favorecendo seus filhos. Hirch ${ }^{18}$ acrescenta que, como conseqüência à socialização desigual de gêneros, essa mãe desenvolve o complexo feminino de inferioridade. Ela tenta manter a "estabilidade e segurança" da família, que representa seu porto seguro. Com a filha adolescente, em muitos casos, a mãe, consciente ou inconscientemente, passa a delegar à filha o seu pesado papel de mãe e esposa, em todos os seus aspectos ${ }^{17}$.

Em algumas situações, quando o incesto é revelado, a mãe reage com ciúmes, como rival e passa a colocar na filha a responsabilidade pelo ocorrido. Para corroborar com essa prática, estaria a dificuldade de a mãe reconhecer o incesto, pois seria o reconhecimento de seu fracasso como mãe e esposa, enquanto que o abusador usa de todos os meios para manter seus atos em silêncio e encobertos ${ }^{18}$.

Outra constatação da complexidade do impacto dessa violência na estrutura familiar é que o incesto é mais freqüentemente relatado em famílias de nível socioeconômico inferior e mais facilmente encoberto pelas de padrão mais alto ${ }^{19}$ (adaptado de Kaplan $\mathrm{H}$ et al.).

É possível, então, concluir que o abuso sexual faz parte de um conjunto de rupturas de relacionamentos, em uma estrutura doente familiar, que vem do histórico de vida de cada membro dessa família, incluindo o agressor. Esse histórico pode determinar uma permissividade ao ato, pela própria desvalorização da infância e adolescência, como também do papel da mulher, mantendo, na maioria dos casos, uma cegueira e surdez coletiva aos apelos, muitas vezes mudos, da vítima.

\section{O diagnóstico}

O diagnóstico do abuso sexual e a conseqüente proteção necessária da criança e do adolescente dependem, também, de o pediatra considerá-lo como uma possibilidade ${ }^{20}$.

\section{Sinais gerais}

O maior problema defrontado pelo médico e pelos meios de proteção legal é a comprovação do abuso sexual quando falta a evidência física. De fato, diferentemente dessa forma de violência, cujo diagnóstico é baseado em conseqüências observadas, o abuso sexual é geralmente definido por meio de sinais indiretos da agressão psicológica somados aos fatos relatados pela vítima ou por um adulto próximo ${ }^{21}$.

Em geral, contatos - oral, digital e genital - ocorrem na genitália externa e na área anal. A não ser que ocorra penetração vaginal, a injúria é limitada à região da vulva e ânus. Quando o perpetrador roça seu pênis na vulva da criança, podem ser evidenciados eritema, edema, lesões e escoriações nos grandes lábios. Achados similares podem ser observados quando o perpetrador manipula digitalmente a vulva ou o intróito vaginal sem que ocorra a penetração.

Porém, as crianças dificilmente revelam de imediato o abuso sexual, o que oportuniza que o processo de cicatrização se complete dentro de poucos dias e, quando ela é examinada posteriormente, a apresentação anatômica da área ano-genital pode já não apresentar lesões evidentes ${ }^{22}$.

Alguns autores tendem a atribuir toda lesão anogenital como sendo causada por abuso. No entanto, estudos atuais demonstram que alguns achados ao exame podem ser variantes da normalidade, enquanto que outros são meramente anormalidades não específicas ${ }^{23,24}$.

O pediatra é freqüentemente o primeiro profissional a ser procurado quando um ou os dois responsáveis, ou ainda outro membro da família, estão preocupados com a possibilidade do abuso sexual. A revisão de experiências sexuais da criança deveria fazer parte da rotina da história médica, e seria obrigatória a investigação mais aprofundada se a criança relatasse sintomas dirigidos à genitália ou ânus e/ou estivesse apresentando comportamento sexualizado adiantado para a idade 25 .

O exame físico de toda a criança e adolescente deve ser completo, e a inspeção dos genitais e ânus, uma rotina. Dessa forma, o profissional familiariza-se com os dados normais e fica mais habilitado e seguro para reconhecer qualquer alteração dessa área ${ }^{26}$.

É causa de preocupação a falta de conhecimento de alguns médicos em reconhecer as diferenças entre o normal e o anormal, principalmente da genitália feminina27,28.

Muitas vezes, a possibilidade oferecida a uma criança de revelação da violência sofrida pode desencadear a denúncia por parte das outras crianças e adolescentes do mesmo ambiente familiar que estejam ou tenham sido submetidos à mesma forma de abuso. Em alguns casos, a descoberta de abuso sexual de uma criança ou adolescente por parte dos responsáveis mais velhos de segunda geração, como avós ou tios-avós, pode levar à quebra da amnésia pós-traumática de um abuso sofrido pela própria mãe ou pai da vítima.

Em outras situações, a criança e/ou adolescente podem ser induzidos a acusar um estranho ou qualquer outro mais distante, que não possam se defender da acusação, encobrindo, assim, o verdadeiro agressor. Habitualmente, são histórias não consistentes e que não se sustentam frente a uma argumentação mais detalhista. Somente quando passam a confiar no profissional é que essas vítimas conseguem revelar o abuso, geralmente repetitivo e de longa duração, perpetrado pelos pais, familiares e outros de seus relacionamentos ${ }^{9}$.

A anamnese deve ser realizada com bastante cautela, devendo-se poupar ao máximo a vítima de estar repetindo sua história, mesmo para profissionais diferentes, pois a fará reviver sua dor e até mesmo potencializá-la, de acordo com a reação e abordagem de cada profissional.

A avaliação da história colhida em momentos diferentes com outras pessoas envolvidas (além do próprio paciente, seus acompanhantes e responsáveis), procurando observar se há incoerências e contradições, pode conduzir ao diag- 
nóstico definitivo. Nem sempre a queixa é clara e, nos casos mais habituais, que são crônicos e sem sinais físicos específicos, a participação de profissional especializado na área emocional, como psicólogos, psiquiatras ou psicanalistas, é fundamental.

O uso de estratégias como brincar com bonecos ou colocar a vítima nos papéis de filha, filho ou responsáveis pode evidenciar alguns sinais ou sintomas. Também nos desenhos, muitas vezes, a criança descreve, até mesmo em detalhes, às vezes simbólicos, todo seu sofrimento.

O conjunto de dados relevantes, se possível com a documentação através de fotos das lesões físicas existentes, devem ser registrados no prontuário do paciente, lembrados os princípios éticos e legais de sigilo e confidencialidade (Manual de Segurança, SBP, 2004) ${ }^{16}$.

Há que se levar em conta, também, a possibilidade de falsa denúncia, na qual a criança ou adolescente é induzido ou convencido a acusar um dos responsáveis em crises conjugais, ou como meio de impedir a guarda daquele filho ou filha, ou mesmo como instrumento de vingança.

As conseqüências da violência sexual na infância ou adolescência podem se apresentar através de sinais e sintomas decorrentes da lesão psicológica a que essas vítimas são submetidas, como tristeza constante, prostração aparentemente desmotivada, sonolência diurna, medo exagerado de adultos, habitualmente aquele do sexo do abusador, história de fugas, comportamento sexual adiantado para idade, masturbação freqüente e descontrolada, tiques ou manias, enurese ou encoprese e baixo amor-próprio.

\section{Sinais específicos}

Embora nem sempre presentes, os sintomas e sinais de lesão física são bastante conclusivos no diagnóstico de abuso sexual na infância e adolescência e devem sempre ser pesquisados.

Há que se levantar o diagnóstico de violência sexual sempre que se encontra:

- Lesões em região genital.

- Edema, hematomas ou lacerações em região próxima ou em área genital, como partes internas de coxas, grandes lábios, vulva, vagina, região escrotal ou anal, tanto em meninas como em meninos.

- Dilatação anal ou uretral, ou rompimento de hímen dão o diagnóstico de abuso sexual, mas esses nem sempre são sinais evidentes dentro das variações da normalidade, necessitando muitas vezes de uma avaliação minuciosa por profissionais especializados da área de perícia médica.

- Lesões como equimoses, hematomas, mordidas ou lacerações em mamas, pescoço, parte interna e/ou superior de coxas, baixo abdome e/ou região de períneo.

- Sangramento vaginal ou anal em crianças pré-púberes, acompanhado de dor, afastados os problemas orgânicos que possam determiná-los.

- Encontro de doenças sexualmente transmissíveis como gonorréia, sífilis, HPV, clamídia, entre outras.
- Aborto - a perda de embrião ou feto, de forma natural ou provocada.

- Gravidez.

Manual de Segurança da Criança e do Adolescente, DCSCA, SBP $2004^{16}$.

\section{Tratamento}

\section{Atendimento inicial}

O acolhimento da criança ou adolescente e de sua dor é o primeiro passo para um bom resultado do tratamento físico e emocional que serão necessários. A escuta de sua história, livre de preconceitos, sem interrupções ou solicitações de detalhamentos desnecessários para a condução médica do caso, vai demonstrar respeito a quem foi desrespeitado no que tem de mais precioso, que é seu corpo, sua imagem e seu amor-próprio.

O pediatra deve lembrar sempre que está diante de uma criança extremamente fragilizada, confusa em seus sentimentos de humilhação, vergonha, culpa, medo e desamparo. É preciso que se crie um bom vínculo, explicando sempre o que será feito e o porquê, nunca prometendo o que não se pode cumprir, como, por exemplo, que essa violência não mais acontecerá, ou que a criança estará sempre protegida.

Deve-se diferenciar a condução do atendimento inicial para as situações agudas do estupro ou outra forma de abuso sexual que são emergenciais e demandam uma seqüência de condutas de assistência imediata, tanto à saúde física como emocional, daquelas crônicas e repetitivas, ambas extremamente desastrosas para a criança ou adolescente.

Nos casos agudos, com menos de 72 horas do ocorrido, as medidas legais já devem acompanhar toda assistência inicial de diagnóstico e tratamento. Para fins de processo judicial e a necessária comprovação da agressão sexual, bem como a confecção de exames que levem à identificação do agressor, é preciso que os responsáveis façam um boletim de ocorrência em delegacia de polícia, que requisitará o laudo pericial do Instituto Médico Legal.

$\mathrm{Na}$ recusa dos responsáveis em fazer a denúncia, a hipótese de autoria, conivência ou impotência deve ser levantada, sendo então obrigatória a presença do Conselho Tutelar, assumindo o poder de tutela provisória pela vítima e o apoio às atitudes de proteção que se fizerem necessárias. Na falta do Conselho Tutelar, a Vara da Infância e Juventude deve ser acionada.

Especial importância deve ser dada às crianças e aos adolescentes portadores de deficiências, que muitas vezes têm seus sinais e sintomas do abuso ignorados por serem considerados parte do quadro da doença principal. Os portadores de deficiências físicas e ou sensoriais são de alto risco para todas as formas de violência, incluindo a sexual, pelo extremo grau de dependência a que estão submetidos em seu dia-a-dia. No caso dos deficientes mentais, a sedução pelo adulto é muito mais fácil, pois a sua idade mental, que não acompanha o desenvolvimento de seu corpo, nem sua situação hormonal, faz com que acreditem cegamente no que esse suposto responsável lhe propuser. 
Todo pediatra deve estar preparado para a realização de exame físico detalhado, incluindo o ginecológico, na busca de eventuais sinais físicos, genitais ou extragenitais de violência. Nos casos mais traumáticos e em situações de descompensação emocional da vítima, o exame deverá ser feito sob sedação e/ou anestesia, com consentimento informado dos responsáveis ou do representante legal da criança. Nos casos de abuso pelos responsáveis, este consentimento deve ser dado pelo Conselho Tutelar ${ }^{16}$.

Nos casos crônicos, infelizmente a maioria, estar-se-á diante de uma criança ou adolescente extremamente fragilizado e que poderá apresentar todos os sinais de destrutividade e autodestrutividade, frutos das seqüelas emocionais do abuso. Os sinais gerais são menos drásticos, mas nem por isso menos graves. A situação familiar deve ser muito bem investigada, procurando se evidenciar, ou não, a participação de outros na manutenção do abuso, seja por impotência, conivência ou negligência.

Há que se avaliar os riscos envolvidos em cada caso e a necessidade de profilaxia para a hepatite $B$, proteção medicamentosa contra as DST não-virais, quimioprofilaxia para a infecção pelo vírus da imunodeficiência humana (HIV) e, para vítimas do sexo feminino em idade procriativa, contracepção de emergência. Essa etapa do atendimento é fundamental para proteger a vítima dos danos e agravos da violência, devendo ser instituída até 72 horas após a violência sexual ${ }^{16}$.

Todo histórico da situação do abuso e suas circunstâncias, bem como os achados do exame físico, os exames diagnósticos realizados e as terapêuticas instituídas devem ser cuidadosamente descritos e registrados em prontuário do paciente. Isso garante a proteção eventualmente necessária nos casos de interesse da Justiça e fornece dados para feitura, com base nas informações do prontuário, do "Laudo Indireto de Exame de Corpo de Delito e Conjunção Carnal"16.

Considera-se que $15 \%$ das vítimas de violência sexual contraem algum tipo de DST, e 1 em cada 1.000 mulheres é infectada pelo $\mathrm{HIV}^{29}$.

É importante lembrar das doenças sexualmente transmissíveis: Neisseria gonorrhoeae, Chlamydia trachomatis, Trichomonas vaginalis, Treponema pallidum, papilomavírus humano (HPV), vírus do herpes simples (HSV), HIV.

Uma descrição detalhada sobre o exame físico e sinais de abuso sexual serão encontrados no Manual de Segurança da Criança e do Adolescente da Sociedade Brasileira de Pediatria (SBP), bem como os tratamentos necessários, padronizados pelo Ministério da Saúde, que os disponibiliza nos centros constituídos como de referência para esse atendimento. Não farão parte do atual artigo por fugirem da extensão deste e já estarem bem documentos na publicação da SBP16.

\section{Instrumentos para proteção legal das vítimas de abuso sexual e onde eles falham...}

A Constituição Federal Brasileira de 1988 coloca, no seu artigo 227, dentre suas leis maiores: "É dever da família, da sociedade e do Estado, assegurar, com absoluta prioridade, o direito à vida, à saúde, à alimentação, à educação, ao lazer, à profissionalização, à cultura, à dignidade, ao respeito, à liberdade e à convivência familiar e comunitária, além de colocá-los a salvo de toda forma de negligência, discriminação, exploração, violência, crueldade e opressão"30.

Em 1990, a 13 de julho, foi sancionada a Lei Federal 8.069, que dispõe sobre o Estatuto da Criança e do Adolescente $^{31}$, estabelecendo seus direitos e deveres, além de fixar as responsabilidades do Estado, da sociedade e da família com o futuro das novas gerações, trazendo uma nova visão e postura frente à infância e adolescência. Traz para todos, a criança e o adolescente, como sujeitos de direito, levando em conta a condição peculiar de seres em desenvolvimento e merecedores de prioridade absoluta.

A expressão "abuso sexual" está presente nos livros de Medicina Legal e no Estatuto da Criança e do Adolescente no artigo $130^{31}$, mas não faz parte das definições de crimes de natureza sexual do Código Penal Brasileiro ${ }^{32}$. Neste, os crimes de natureza sexual são qualificados como: estupro, atentado violento ao pudor, sedução, posse sexual mediante fraude, atentado ao pudor, assédio sexual, corrupção de menores, rapto violento ou mediante fraude, tendo sido retirado do Código Penal Brasileiro, neste ano, o artigo sobre o rapto consensual ${ }^{32}$.

O estupro é definido, pelo Código Penal Brasileiro, pela penetração vaginal com uso de violência ou grave ameaça, sendo que, em menores de 14 anos, essa violência é presumida ${ }^{32}$.

Habitualmente, as formas iniciais do abuso sexual como apresentação de violência doméstica são praticados de forma insidiosa e progressiva, usando o agressor de várias formas de aproximações, intimidações e até ameaças, como já ressaltado, nem sempre acompanhadas de violência física.

O atentado violento ao pudor caracteriza-se pela obrigação de alguém a praticar atos libidinosos, sem penetração vaginal, utilizando violência ou grave ameaça, sendo também presumido quando em menores de 14 anos $^{32}$.

Em todos os casos de abuso sexual, é imprescindível que o médico, em especial o pediatra, esteja capacitado para o manejo clínico e psicológico das vítimas, incluindo o conhecimento da legislação específica. Isso exige que tenha sensibilidade, disponibilidade e experiência. A negligência nesses aspectos pode ser interpretada pelo paciente como novo processo de "vitimização", também pelo serviço de saúde.

No abuso sexual da criança e adolescente, o ato libidinoso é o mais freqüente. Inicialmente, através de manobras de sedução e intimidação, seguidas de ameaças à própria criança ou a algum membro de sua família, comumente à mãe, o agressor obriga essa criança a praticar atos sexuais que não incluam a penetração vaginal para não caracterizar o estupro, mas sim uma série das mais variadas formas de contato sexual, constantemente incluindo sexo oral e penetração anal.

Assim diagnosticados, os poucos casos que chegam à denúncia e aos meios legais, que deveriam ser de prote- 
ção, acabam por ter laudo pericial inconclusivo ou de atos libidinosos, que não deixam marcas físicas, nem a comprovação pelos critérios atuais implícitos no Código Penal. Este define como grave as lesões essencialmente corporais, como as que resultam em incapacidade para as ocupações habituais por mais de 30 dias, em perigo de vida, perda ou debilidade de membro, sentido ou função, aceleração de parto, incapacidade para o trabalho, enfermidade incurável, deformidade permanente, aborto ou se resulta em morte 32 .

Tais artigos, escritos em 1940 e, portanto, definidos com o pouco saber da época sobre as características especiais de um ser em desenvolvimento, têm sido usados como modelos nos laudos periciais do Instituto Médico Legal. Esses laudos, baseados unicamente nos achados de lesões físicas, ignoram a possibilidade de lesões emocionais, que deixarão marcas definitivas se não tratadas. Porém, eles têm sido o principal instrumento judicial de graduação das ações violentas, submetendo aos mesmos critérios tanto o adulto como as crianças e adolescentes, em todos os processos penais.

Essa seqüência de avaliações incompletas das marcas físicas e emocionais, determinadas pela violência sexual a uma criança ou adolescente, demonstram as falhas nos meios legais que deveriam ser de prioridade para proteção absoluta da infância e adolescência. Não há como se avaliar, com as mesmas medidas, os danos e riscos conseqüentes a uma agressão contra um adulto àquelas contra uma criança ou adolescente, seja ela física, psicológica, sexual ou negligência.

Maior gravidade ainda por serem formas de maustratos, nas quais o agressor é o responsável ou está ligado à criança pelos laços familiares ou de dependência.

A falta ou inconclusão do ato pericial legal faz com que, em muitos casos, não se consiga a culpa do abusador e, com isso, a proteção da vítima, a qual permanece muitas vezes sob o mesmo teto e com a mesma dependência, com a violência então potencializada pela falta de punibilidade após o ato criminoso ser delatado.

\section{Prognóstico}

É preciso que se tenha sempre presente que todas as formas de abuso sexual podem levar à desestruturação evolutiva da criança ou adolescente e que o diagnóstico de que não houve penetração vaginal (caracterizando o estupro) não deve ser minimizado, ou dado a ele uma conotação mais branda do que a realidade. Tanto o abuso sexual com penetração vaginal ou anal, com ou sem penetração, ou através de outros meios de agressões ligadas à esfera sexual, são formas doentias e perversas de violência à criança e ao adolescente, que deixam marcas definitivas no seu desenvolvimento físico e emocional.

Com a evolução do incesto e com a adolescência, o agressor, com maior incidência o companheiro da mãe, padrasto ou pai, torna-se cada vez mais violento e possessivo, com medo que a sua vítima o denuncie, ou que possa perdê-la para outros, passando a interferir nos relaciona- mentos de sua ou seu dependente com seus pares e sociedade. Dificulta ou impede que vá à escola, freqüente ambientes sociais e de lazer, que tenha amizades ou qualquer outra forma de relacionamento, escravizando-a em seus domínios.

Essa seqüência vai provocar uma cascata de reações de autodefesa ou de autodestruição, na dependência da assistência e proteção oferecidas a essas vítimas.

$A$ vulnerabilidade às seqüelas do abuso sexual depende do tipo de abuso, de sua cronicidade, da idade da vítima e do relacionamento geral que tem com o agressor. Seus efeitos podem ser devastadores e perpétuos ${ }^{19}$, não estando descrito, no entanto, nenhum sintoma psiquiátrico específico resultante do abuso sexual.

Segundo Kaplan et al., em seu capítulo "Problemas Relacionados ao Abuso ou Negligência", as crianças com menos de 3 anos de idade tendem a não produzir uma recordação verbal de traumas ou abusos passados, contudo suas experiências podem ser reproduzidas em seus jogos ou fantasias $^{19}$.

Na idade pré-escolar, a imaturidade do desenvolvimento cognitivo e a pouca percepção que as crianças têm do mundo, aliadas à dificuldade de linguagem, também dificultam a compreensão dos fatos e, em conseqüência, a denúncia, acompanhamento e avaliação dos casos.

Na fase escolar e da adolescência, a vergonha, culpa e a sensação de desproteção ou conivência pelos outros responsáveis, somadas à incompletude da formação dos valores morais (maior ou menor, dependendo do meio familiar e dos vínculos afetivos), além da dificuldade ou impossibilidade de diálogo com pais ou responsáveis não envolvidos diretamente no abuso, tornam a denúncia um fato raro.

O abuso sexual deve ser considerado um fator predisponente a sintomas posteriores, como fobias, ansiedades e depressão, bem como envolvimento de um transtorno dissociativo de identidade, também conhecido como transtorno de personalidade múltipla com possibilidade de comportamento autodestrutivo e suicida.

Os melhores resultados no acompanhamento das vítimas de abuso sexual são esperados quando as crianças estão cognitivamente intactas, o abuso é reconhecido e interrompido em fase precoce e toda família participa do tratamento.

\section{Conclusões}

É esperado que todo pediatra, dentro de seu papel e dever profissional, seja capaz de atuar para a prevenção do abuso sexual, de diagnosticar o risco e levantar a suspeita precocemente, quando a situação de violência já está instalada, chegando ao diagnóstico e à denúncia em tempo hábil, para que possa garantir a integridade física e emocional da criança ou adolescente sob seus cuidados. Dessa forma, a partir do atendimento de rotina, emergencial ou de acompanhamento, ele poderá desencadear todos os meios de proteção legal e social existentes, que devem garantir, 
ao mínimo, o tratamento daquela criança ou adolescente, sua proteção, apoio e assistência familiar, bem como o afastamento do agressor.

A atenção continuada e especializada da saúde física e emocional da criança e/ou adolescente vítimas de abuso sexual, bem como de sua família, por equipe interdisciplinar será sempre necessária. De sua qualidade dependerá o restabelecimento da auto-estima e da integridade física e psíquica das vítimas, reestruturando sua confiança nas pessoas e sua capacidade de lutar dignamente pela vida.

Além do dever ético, legal e moral, todo pediatra deve saber da importância de sua intervenção na prevenção ou interrupção do abuso sexual na infância e adolescência.

Desse olhar diferenciado, que pode enxergar detalhes e ouvir as queixas de dores não faladas, seguido do desencadeamento de todas as medidas de proteção necessárias, novos e bons caminhos poderão ser criados para essas crianças e adolescentes.

É preciso que o pediatra se conscientize, ao receber uma criança ou adolescente com alguns dos sinais apresentados, ou ao levantar a suspeita do abuso, mesmo através de poucas ou aparentemente infundadas queixas trazidas por uma criança em sofrimento, que essas vítimas de uma das formas de maus-tratos mais desestruturantes de personalidade, estão buscando nele uma esperança de que rompa o pacto do silêncio que envolve a família incestuosa e seu meio. Procuram alguém que as defendam!

Muitas dessas vítimas, se abandonadas à sua sorte, vão levar essa criança ferida dentro de si e todas as suas dores e seqüelas para toda a vida.

\section{Referências}

1. Lévi-Strauss C. Las estructuras elementales del parentesco. $2^{a}$ ed. Barcelona, Espanha: Paidos Ibérica; 1981. p. 79-90.

2. Freud S. Totem y tabu. In: Obras completas de S. Freud. Tomo XIII. $1^{a}$ ed. Buenos Aires: Amorrortu Editores; 1980. p. 11-26.

3. ABRAPIA. Abuso Sexual: Guia para orientação para profissionais da Saúde. Rio de Janeiro: Autores e Agentes Associados; 1997.

4. Berliner L, Conte JR. The effects of disclosure and intervention on sexually abused children. Child Abuse Negl. 1995;19:371-84.

5. Hornor G. Child sexual abuse: psychosocial risk factors. J Pediatr Health Care. 2002;16:187-92.

6. Scherer CC, Machado DS, Gauer GJ. Uma violência obscura: abuso sexual. In: Gauer GJ, Machado DS, orgs. Filhos \& vítimas do tempo da violência. Curitiba: Juruá; 2003. p. 32-44.

7. Kristensen CA. Abuso sexual em meninos [dissertação]. Porto Alegre: Universidade Federal do Rio Grande do Sul; 1996.

8. Whiffen VE, MacIntosh HB. Mediators of the link between childhood sexual abuse and emotional distress - a critical review. Trauma Violence Abuse. 2005;6:24-39.

9. World Health Organization. Guidelines for medico-legal care for victims of sexual violence. 2003:8.
10. Berliner L, Conte JR. The effects of disclosure and intervention on sexually abused children. Child Abuse Negl. 1995;19:371-84.

11. Braun S. A violência sexual infantil na família - do silêncio à revelação do segredo. Porto Alegre: AGE; 2002. p. 102.

12. Johnson CF. Child sexual abuse. Lancet. 2004;364:462-70.

13. Briere J, Elliott D. Prevalence and psychological sequelae of selfreported childhood physical and sexual abuse in a general population sample of men and women. Child Abuse Negl. 2003;27:1205-22.

14. DECA - Departamento Estadual da Criança e do Adolescente da Polícia Civil. Secretaria de Segurança Pública. Rio Grande do Sul (Brasil). Relatório anual de 2002/2003/2004.

15. Banco de Dados, SMS, FAS Curitiba, Relatórios da Rede de Proteção às Crianças e Adolescentes em Situação de Risco para Violência, Prefeitura Municipal de Curitiba, 2002,2003.

16. Pfeiffer $L$, Waksman R. Violência na Infância e Adolescência. Manual de Segurança da Criança e do Adolescente, Sociedade Brasileira de Pediatria. São Paulo, 2004;195-267.

17. Felizardo D, Zürcher E, Melo K. Modelos Teóricos de Interpretação para Violação do Incesto, Do Medo e Sombra. Natal, RN: AS Editores; 2003. p. 49-51.

18. Hirch M. Realer inzest. Berlin, Heidelberg: Springles Verlag; 1990.

19. Kaplan H, Sadock B, Grebb J. Problemas relacionados ao abuso ou negligência. In: Kaplan \& Sadock. Compêndio de Psiquiatria. $7 a$ ed. Porto Alegre: Artes Médicas; 1997. p. 738-744.

20. American Academy of Pediatrics. Guidelines for the Evaluation of Sexual Abuse of Children, Committee on Child Abuse \& Neglect. Pediatrics. 1991;87:254-60.

21. Dubé $R$, Hébert $M$. Sexual abuse of children under 12 years of age: a review of 511 cases. Child Abuse Negl. 1988;12:321-30.

22. Heger A, Ticson L, Velasquez O, Bernier R. Children referred for possible sexual abuse: medical findings in 2384 children. Child Abuse Negl. 2002;26:645-59.

23. Muran DJ. Mini-review: the medical evaluation in cases of child sexual abuse. J Pediatr Adolesc Gynecol. 2001;14:55-64.

24. Johnson CF. Child sexual abuse. Lancet. 2004;364:462-70.

25. Heger A, Ticson L, Velasquez O, Bernier R. Children referred for possible sexual abuse: medical findings in 2384 children. Child Abuse Negl. 2002;26:645-59.

26. Strickland J, Adams JA. Medical evaluation of suspected child sexual abuse. J Pediatr Adolesc Gynecol. 2004;17:191.

27. Lentsch KA, Johnson CF. Do physicians have adequate knowledge of child sexual abuse? The results of two surveys of practicing physicians, 1986 and 1996. Child Maltreat. 2000;5:72-8.

28. Dubow SR, Giardino AP, Christian CW, Johnson CF. Do pediatric chief residents recognize details of prepubertal female genital anatomy: a national survey. Child Abuse Negl. 2005;29:195-205.

29. Manual do Programa de Atenção à Mulher Vítima de Violência, SMS - Curitiba, 2002.

30. Constituição Federal do Brasil. Artigo 227. Brasília,1988.

31. Estatuto da Criança e do Adolescente, COMTIBA, Curitiba. Publicado em Diário Oficial da União 1990.

32. Código Penal Brasileiro. Dos crimes contra os costumes, Maus tratos, Tipificação de lesões. 39a ed. São Paulo; 2002.

Correspondência:

Edila Pizzato Salvagni

Professor Guerreiro Lima, 733

CEP 91530-190 - Porto alegre, RS

Tel.: (51) 3339.1039

E-mail: edilaps@brturbo.com 